\title{
Hydrolysis of Straw in Ionic Liquids with Acid as Catalyst under Microwave Irradiation
}

\author{
Yuanjing Zhang, Gang Wei, Guangyi Yu, and Ning Qiao \\ State Key Laboratory of Chemical Resource Engineering, Beijing University of Chemical Technology, Beijing 100029, China \\ Correspondence should be addressed to Ning Qiao; qiaoning_buct@163.com
}

Received 16 September 2014; Accepted 1 December 2014

Academic Editor: Han Ning

Copyright (C) 2015 Yuanjing Zhang et al. This is an open access article distributed under the Creative Commons Attribution License, which permits unrestricted use, distribution, and reproduction in any medium, provided the original work is properly cited.

With ionic liquids as solvents and corn straw as raw material, different processes of lignocellulose pretreatment with acid as catalyst were studied under conventional heating/microwave irradiation and the reducing sugar was measured. The results indicated that acid can accelerate hydrolysis reaction of corn straw into reducing sugar with ionic liquids as solvent, and microwave irradiation was more efficient in pretreatment of corn straw than conventional heating. The influences of different acid catalysts, the concentration of acid, temperature, mass ratio of straw $/[\mathrm{Bmim}] \mathrm{Cl}$, and the amount of refill water were mainly tested, and the optimum experimental conditions are thus determined.

\section{Introduction}

Biomass resource is a kind of renewable resources to meet the requirements of sustainable development, which has attracted considerable attention [1]. Lignocellulose, as the most abundant and cheapest biomass resources on the earth, can be turned into commodity chemicals and a variety of biological fuels [2] such as biodiesel, ethanol, and butanol, by biological or chemical means, which is considered an effective way to replace fossil energy and alleviate the problem of energy crisis. It is difficult for reagent to reach cellulose because of high crystallinity of lignocellulose in natural biomass. Therefore, pretreatment of lignocellulosic biomass prior to use as feedstock for biofuel and chemical production is required to either disrupt the crystalline structure of cellulose, remove hemicellulose, or remove or modify the lignin, to increase the exposure of the cellulosic substrate to hydrolytic enzymes, decrease cellulosic substrate recalcitrance for enzyme attack, and thus increase glucose yield [3-5].

Since Rogers found that the ionic liquids (ILs) can dissolve cellulose in 2002 [6], in the use of ILs dissolving cellulose, a lot of fruitful works have been carried out both at home and abroad [7-9]. Recently, new attention has been focused on the pretreatment of lignocellulosic biomass in ILs $[7,10]$ because of the ability of some ILs to dissolve cellulose under moderate conditions and the possibility of recovering nearly $100 \%$ of the IL in its initial purity [11]. ILs are liquids at room temperature or near room temperature composed of ions [10]. As a new type of green solvent, ILs are nonflammable and possess many good qualities such as a very low vapor pressure, good thermal stability, and recycled performance. Depending upon the ILs used, lignocellulosic biomass may be completely dissolved by the ILs and subsequently regenerated by adding antisolvents such as water [7]. It has been demonstrated that cellulose reprecipitated after dissolution in ILs exhibits much higher enzymatic hydrolysis owing to its decreased crystallinity [12]. However, the high cost, high viscosity, and troublesome separation of ILs still hamper their commercialized application. To overcome these problems, several trials [13-16] were performed to develop the hydrolysis of cellulose catalyzed by some solid acids, but this heterogeneously catalytic process shows relatively low hydrolysis efficiency due to mass transfer resistance between solid acids and insoluble cellulose in water.

Microwave heating is based on an internal heating process based on the direct absorption of energy by polar molecules, which differs from conventional heating that is based on heat transfer. Some studies have showed that microwave irradiation enhances the dissolution of lignocellulosic materials in 
IL and subsequent fractionation of cellulose and lignin [1720]. Moreover, with regard to its application to IL-assisted biomass pretreatment for subsequent enzymatic hydrolysis, it has been recently demonstrated that microwave irradiation can facilitate the pretreatment of cellulose in IL [21, 22].

In the present study, with corn straw as raw material, a more effective lignocellulosic biomass pretreatment process was developed using a commonly researched IL, 1-butyl-3methylimidazolium chloride (BMIMCl), as a model IL and an acid catalyst under microwave irradiation. The influence of different pretreatment scheme on straw hydrolysis was studied, and the role of heating mode played on lignocellulose conversion was examined with ILs as solvents; at the same time, the straw pretreatment process was optimized.

\section{Materials and Methods}

2.1. Material. Straw was used as a model lignocellulosic material (collected from Hebei province in China). The straw was washed with a lot of water, air-dried to constant weight, and milled and screened into powder with particle sizes between 2.50 and $5 \mathrm{~mm}$ and then was collected and stored at room temperature in a sealed container. $\mathrm{N}$-Methylimidazole, chlorinated n-butane, sodium hydroxide, phenol, sodium sulfate, and potassium sodium tartrate were provided by Beijing chemical reagent factory. Nitrosalicylic acid and sulfuric acid were purchased from Beijing Chemical Works. All the chemicals used in this study were of analytical grade. Microwave heating device was self-designed, which included a microwave oven (MM721NG1-PW, purchased from Midea Corporation), a circular waveguide, and a stirrer device.

\subsection{Preparation of 1-Butyl-3-methylimidazole Chloride} ([Bmim]Cl) IL. The N-methylimidazole and chlorinated nbutane reacted for about $48 \mathrm{~h}$ in mole ratio of $1: 1$ at $70^{\circ} \mathrm{C}$ under nitrogen atmosphere. At the end of the reaction a layered mixture was obtained and then the mixture was filtered with a funnel and the lower liquid was product. After that the product was washed with ethyl acetate and purified under rotary evaporation, and the final product was obtained after vacuum drying and stored for use.

2.3. Acid Catalyzed Hydrolysis in IL. Hydrolysis reaction of straw in IL phase was carried out under the environment of airtight and constant pressure. The IL ([Bmim]Cl) and dry straw were added to a reactor in a certain ratio, then certain amount of water and acid catalyst were added, and the reactor was sealed and heated to certain temperature ((1) in water phase as conventional heating means; (2) under certain gear of microwave oven in an intermittent way and different gear corresponding to different power) and kept for 2 hours. (Adding acid to the preheated sample was determined as starting time for reaction.) Electromagnetic stirring speed was controlled at $300 \mathrm{r} / \mathrm{min}$ during reaction, and the speed may be increased $(<600 \mathrm{r} / \mathrm{min})$ if straw dissolution effect is not good or no monosaccharide is detected. A certain amount of hydrolysate was diluted with water after reaction, and contents of reducing sugar of the diluted solution were detected by using the DNS method.
2.4. DNS Analysis and Calculation of Total Reducing Sugar. The yield of TRS (total reducing sugar) was determined with 3,5-dinitrosalicylic acid colorimetric method (DNS method). (When glucose was used as standard, coefficient 0.9 was introduced in the TRS calculation formula to correct the concentration of reducing sugar because the type of sugar in actual product is more than that). Finally the proportion of the quality of reducing sugar to total straw was used as measurement:

$$
\mathrm{TRS}=\frac{m_{1} \times n}{m_{2}} \times 0.9 \times 100 \%,
$$

where TRS is the yield of total reducing sugar, $m_{1}$ is the quality of reducing sugar, $n$ is dilution ratio, and $m_{2}$ is the quality of sample straw.

2.5. SEM Analysis of Straw. SEM was used to record the surface morphological features of straw before and after pretreatment. The samples were coated with gold using a Leica EMS CD 005 system prior to analysis by S-4700 scanning electron microscope (magnification: 20 500,000 times; accelerating voltage: $0.5 \mathrm{kV} \sim 30 \mathrm{kV}$, Hitachi LTD., JP).

\section{Results and Discussion}

3.1. Comparison of Straw Acid Hydrolysis Experiment Scheme. Table 1 shows 7 groups of different experimental scheme by changing different system under different heating modes. In the above different experimental scheme the average reducing sugar yield and the time reached maximum reducing sugar yield were got under the same experimental condition groups.

The data of groups 1 and 4 and groups 2 and 3 show that reducing sugar yield of straw pretreated in IL is higher than that in water system, and data of groups 1 and 3 and groups 2 and 4 show that microwave heating way not only can greatly shorten the reaction time required but also can effectively improve the reducing sugar yield compared with the traditional heating mode, and the maximum TRS is $35.5 \mathrm{wt} \%$. And data in group 5 shows that TRS can be $40.7 \mathrm{wt} \%$ if straw was first treated in IL and then hydrolyzed in water. According to data of group 6, a mixture of IL and water system has no advantage, and the reducing sugar yield is only $25.1 \mathrm{wt} \%$.

In the system of [Bmim] Cl IL as solvent, $\mathrm{Cl}^{-}$, and hydrogen atoms of hydroxyl in cellulose macromolecular chain to form hydrogen bonding, hydrogen bonding network of cellulose is thus interrupted, and the cellulose chain is fully exposed in the attack of $\mathrm{H}^{+}$, so the reaction rate is faster and reducing sugar yield is high [23].

By microwave radiation heating hydrolysis of the reducing sugar yield increased significantly; this may be on the one hand because the microwave radiation heating does not depend on the temperature gradient, as a result the system is heated evenly, and on the other hand macromolecular ILs can absorb microwaves better, which heats up quickly, and the reducing sugar yield was increased [24]. Therefore, in the [Bmim] Cl, IL medium with microwave radiation heating can promote acid hydrolysis of the straw. 
TABLE 1: Hydrolysis of straw in different ways.

\begin{tabular}{lclcc}
\hline & Solvent & Heat & Time $[\mathrm{min}]$ & Yield \\
TRS $[\mathrm{wt} \%]$ \\
\hline 1 & IL & Microwave & 7 & 35.5 \\
2 & Water & Traditional & 240 & 19.8 \\
3 & IL & Traditional & 120 & 30.5 \\
4 & Water & Microwave & 45 & 24.4 \\
$5^{\mathrm{a}}$ & IL (first) + water (last) & Microwave & $7+45$ & 40.7 \\
$6^{\mathrm{b}}$ & Water (50 wt\%) + IL (50 wt\%) & Microwave & 45 & 25.1 \\
\hline
\end{tabular}

${ }^{a}$ Dealing in IL for $7 \mathrm{~min}$ and then in water phase system for $45 \mathrm{~min}$.

${ }^{\mathrm{b}}$ Dealing directly in the mixed system of IL and water with proportion $1: 1$ to each other.

TABLE 2: Hydrolysis of straw by different acid catalyst.

\begin{tabular}{lccc}
\hline & Catalyst & Time $[\mathrm{min}]$ & Yield $_{\text {TRS }}[\mathrm{wt} \%]$ \\
\hline 1 & $\mathrm{HCl}$ & 30 & 34.4 \\
2 & $\mathrm{HNO}_{3}$ & 30 & 26.7 \\
3 & $\mathrm{H}_{2} \mathrm{SO}_{4}$ & 30 & 35.5 \\
4 & $\mathrm{H}_{3} \mathrm{PO}_{4}$ & 30 & 13.6 \\
\hline
\end{tabular}

At the end of the reaction a part of cellulose does not hydrolyze, but crystallinity is significantly lowered, and structure becomes loose, so hydrolysis in water can further improve the reducing sugar yield.

3.2. Effect of Different Factors on the Straw Hydrolysis. On the basis of the experiment scheme established in Section 3.1, namely, in IL system, with the method of microwave heating, different kind of acid catalyst, acid concentration, temperature, straw to IL mass ratio, and the influence of water supplement were investigated.

3.2.1. Influence of Different Kinds of Acid on the Straw Acid Hydrolysis System. Four different kinds of acids $\left(\mathrm{H}_{2} \mathrm{SO}_{4}\right.$, $\mathrm{HCl}, \mathrm{HNO}_{3}$, and $\mathrm{H}_{3} \mathrm{PO}_{4}$ ) were used as catalysts in $\mathrm{BMIMCl}$ solutions for pretreatment of straw. The pretreatment was carried out under microwave heating, acid concentration $0.5 \mathrm{wt} \%$, straw to IL mass ratio of 0.08 , and the straw to filling water mass ratio of 0.25 . Table 2 showed the average reducing sugar yield and the time needed for reaching maximum reducing sugar yield using different acid as a catalyst under the condition of six sets of experiments.

As shown in Table 2, in the same reaction time, the highest reducing sugar yield can be obtained when $\mathrm{H}_{2} \mathrm{SO}_{4}$ is used as catalyst. Similar effect can be found when $\mathrm{HCl}$ was used as catalysts. However, $\mathrm{HCl}$ is easy to be volatile because of the high temperature in the reaction system, and more water was added to the system since HCI is stored in the form of hydrochloric acid, the water content of which is more than $62.5 \mathrm{wt} \%$. Moreover, the amount of hydrogen ions for $0.5 \%$ $\mathrm{H}_{2} \mathrm{SO}_{4}$ is higher than that of $0.5 \% \mathrm{HCl} . \mathrm{HNO}_{3}$ and $\mathrm{H}_{3} \mathrm{PO}_{4}$ took the third and the fourth place. Because $\mathrm{HNO}_{3}$ shows strong oxidation activity, side reactions may occur with some reducing sugar. And $\mathrm{H}_{3} \mathrm{PO}_{4}$ has poor $\mathrm{H}^{+}$donor ability due

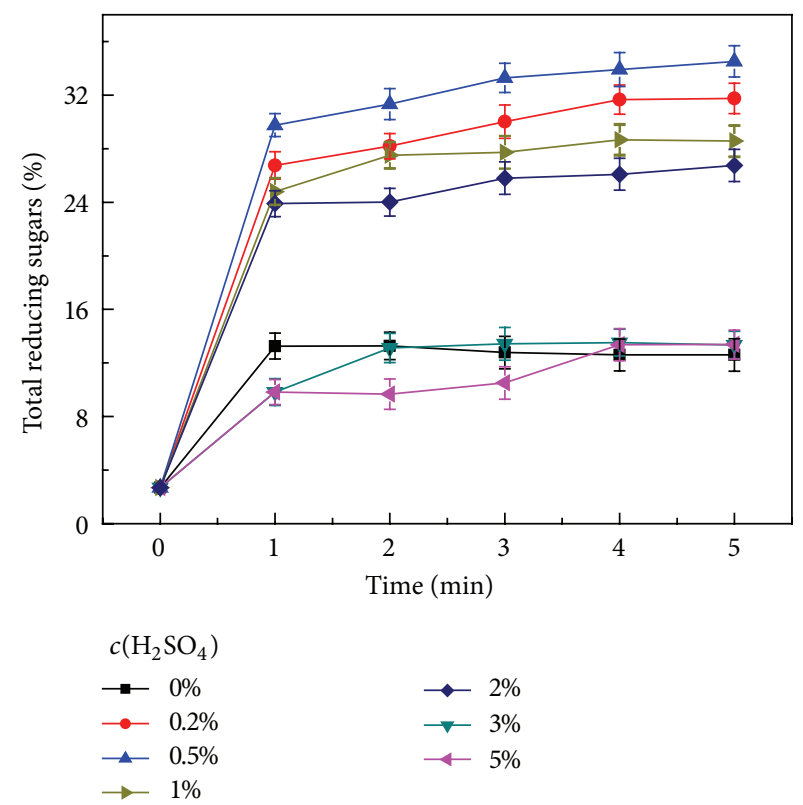

FIGURE 1: Influence of acidity on reducing sugar concentration.

to its subacidity. For the above reasons, we choose $\mathrm{H}_{2} \mathrm{SO}_{4}$ as catalyst in pretreatment of straw in ILs.

3.2.2. Influence of $\mathrm{H}_{2} \mathrm{SO}_{4}$ Concentration on the Straw Acid Hydrolysis System. Under the condition of ILs as solvent, microwave heating, reaction temperature $150^{\circ} \mathrm{C}$, straw to IL mass ratio of 0.08 , and the straw to filling water mass ratio of 0.25 , influence of $\mathrm{H}_{2} \mathrm{SO}_{4}$ concentration was investigated (Figure 1). The yield of reducing sugar increased first and then decreased with the increase of acid concentration. Figure 1 showed that low $\mathrm{H}_{2} \mathrm{SO}_{4}$ concentration has an obvious advantage. The yield of reducing sugar was low without addition of $\mathrm{H}_{2} \mathrm{SO}_{4}$; with the increase of $\mathrm{H}_{2} \mathrm{SO}_{4}$ concentration, it got the maximum when $\mathrm{H}_{2} \mathrm{SO}_{4}$ concentration was $0.5 \mathrm{wt} \%$. However, when $\mathrm{H}_{2} \mathrm{SO}_{4}$ concentration increased to $1 \%$, TRS began to decrease. The yield was half the maximum when $\mathrm{H}_{2} \mathrm{SO}_{4}$ concentration reached $3 \mathrm{wt} \%$, and when $\mathrm{H}_{2} \mathrm{SO}_{4}$ concentration is $5 \mathrm{wt} \%$, the yield became lower. This indicated that $\mathrm{H}_{2} \mathrm{SO}_{4}$ concentration has optimum value, which may be $0.5 \% \mathrm{wt} \% . \mathrm{H}^{+}$donated by acid played a role of catalyst during 


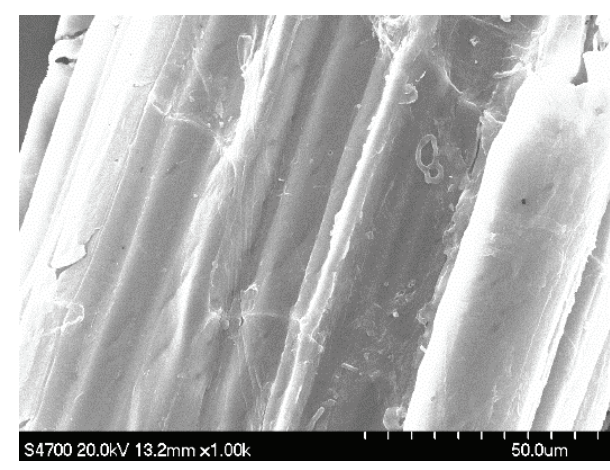

(a)

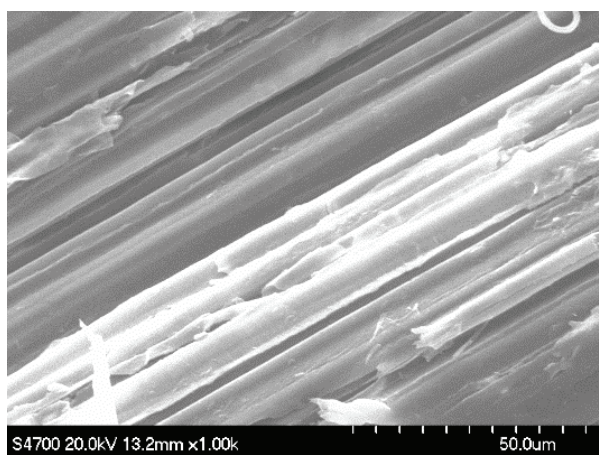

(c)

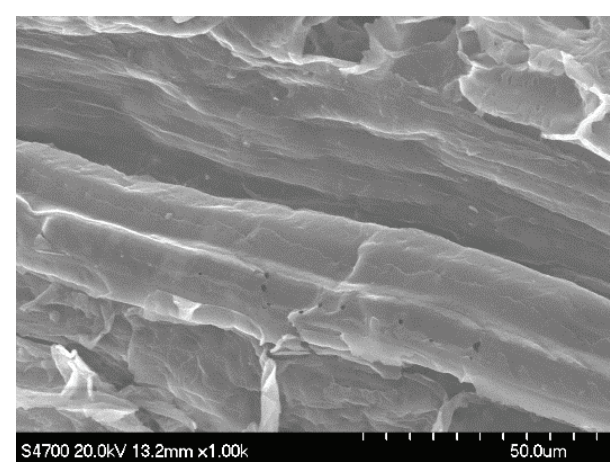

(b)

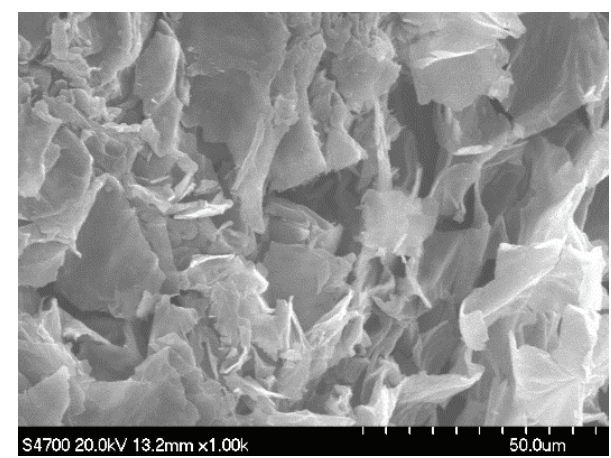

(d)

FIGURE 2: SEM of (a) untreated straw; (b) straw pretreated with water containing $0.5 \% \mathrm{H}_{2} \mathrm{SO}_{4}$; (c) straw pretreated with IL; (d) straw pretreated with BMIMCl solution containing $0.5 \% \mathrm{H}_{2} \mathrm{SO}_{4}$.

the reaction. Low concentration acid in the IL system has a high activity and could accelerate the cellulose hydrolysis.

Figure 2 showed the morphology of straw pretreated in different conditions. The structure of untreated straw surface is compact and orderly arranged, and the texture is hard, which resulted in the weak contact of solution with cellulose. Therefore hydrolysis reaction is weak. The surface of straw becomes cracking and the cross section is layered after being pretreated by $0.5 \mathrm{wt} \% \mathrm{H}_{2} \mathrm{SO}_{4}$, and this structure helps solution contact with cellulose which is good for hydrolysis reaction. When pretreated with $\mathrm{IL}$, the cracking in the surface of straw is more serious than that pretreated with 0.5 wt $\% \mathrm{H}_{2} \mathrm{SO}_{4}$ and peels off, thus makes cellulose more exposed which is helpful for IL contact with cellulose and hemicellulose, and promotes the hydrolysis process. When pretreated with IL added with acid catalyst, the surface of straw is seriously damaged and is rupture in flocculent state, which further removes the lignin and hemicellulose shielding of cellulose and release cellulose to a great extent, and thus is advantageous to the hydrolysis reaction. From Figure 2 we can see that IL with acid as catalyst is a good solvent for the hydrolysis of straw.

3.2.3. Influence of Microwave Heating on the Straw Acid Hydrolysis System. Under the condition of ILs as solvent, microwave heating, $\mathrm{H}_{2} \mathrm{SO}_{4}$ concentration $0.5 \mathrm{wt} \%$, straw to IL mass ratio of 0.08 , and the straw to filling water mass ratio of 0.25 , influence of reaction temperature was investigated

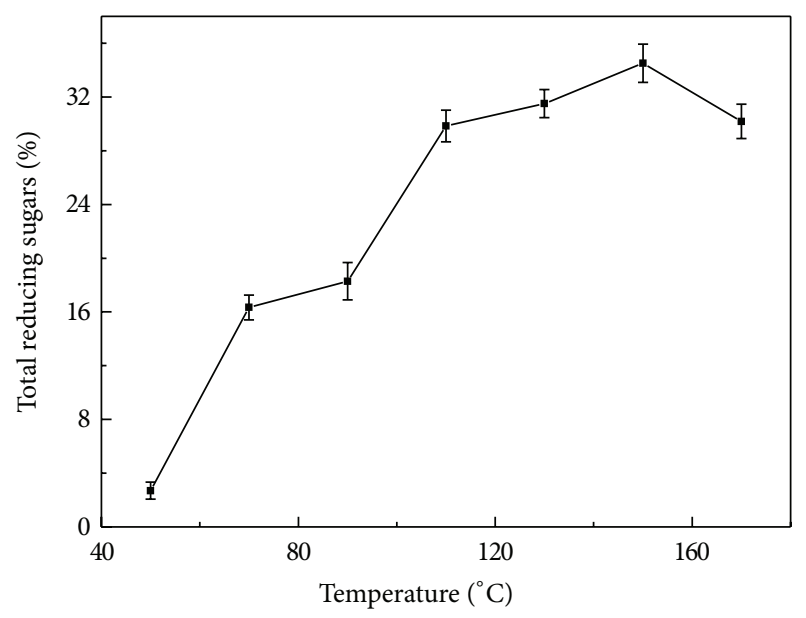

FIGURE 3: Influence of temperature on reducing sugar concentration.

(Figure 3 ). The yield of reducing sugar gets the maximum $(35.5 \mathrm{wt} \%)$ at the reaction temperature $150^{\circ} \mathrm{C}$. The yield is low under the temperature of $70^{\circ} \mathrm{C}$ because low temperature could not break the crystal structure of cellulose. When the temperature is higher than $100^{\circ} \mathrm{C}$, the yield increases with the increasing of the temperature. This shows that the cellulose hydrolysis occurs obviously. However, when the temperature is higher than $170^{\circ} \mathrm{C}$, the ILs are easy to decompose and 


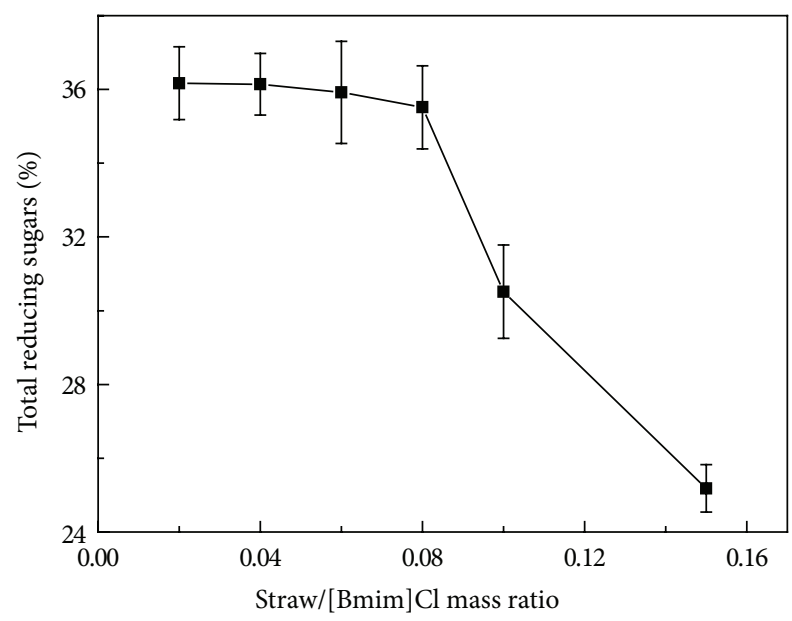

Figure 4: Reducing sugar concentration in different straw/ $[\mathrm{Bmim}] \mathrm{Cl}$.

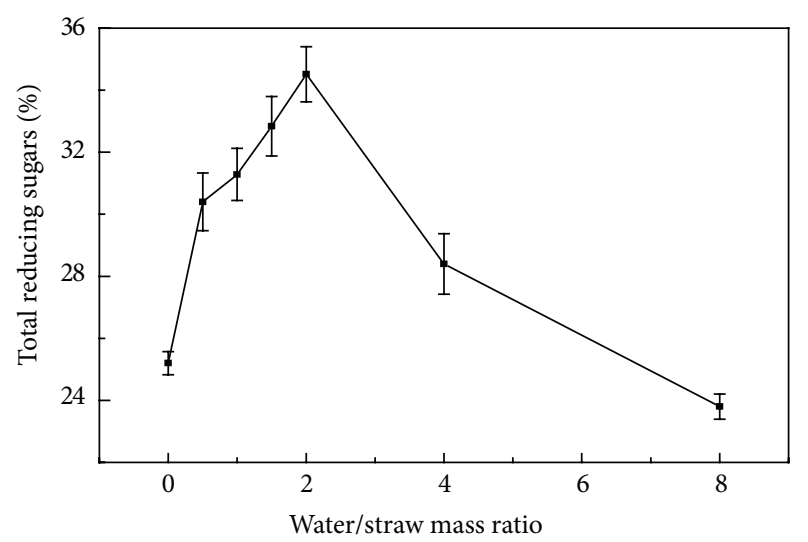

FIGURE 5: Influence of water/straw mass ratio on reducing sugar concentration.

the straw is easy to carbonize. Therefore the best hydrolysis reaction temperature is $150^{\circ} \mathrm{C}$.

3.2.4. Influence of Straw to IL Mass Ratio on the Straw Acid Hydrolysis System. Under the condition of ILs as solvent, microwave heating, $\mathrm{H}_{2} \mathrm{SO}_{4}$ concentration $0.5 \mathrm{wt} \%$, reaction temperature $150^{\circ} \mathrm{C}$, and the straw to filling water mass ratio of 0.25 , influence of straw to IL mass ratio was investigated (Figure 4). The yield of reducing sugar gets the maximum at straw to IL mass ratio of 0.08 . No obvious change was obtained below this level. And the yield reduces quickly when the ratio is higher than 0.08 .

3.2.5. Influence of the Straw to Filling Water Mass Ratio on the Straw Acid Hydrolysis System. Under the condition of ILs as solvent, microwave heating, $\mathrm{H}_{2} \mathrm{SO}_{4}$ concentration $0.5 \mathrm{wt} \%$, reaction temperature $150^{\circ} \mathrm{C}$, and the straw to IL mass ratio of 0.08 , influence of straw to filling water mass ratio was investigated (Figure 5). The yield of reducing sugar gets the maximum at straw to filling water mass ratio of 0.25 . The reaction system still can get a high yield when the filling water is little. Even though no filling water is added, a yield of $25 \mathrm{wt} \%$ was got since the dehydration of oligosaccharides (e.g., monosaccharide and disaccharide) to 5-hydroxymethylfurfural (5-HMF) can provide water. An appropriate amount can accelerate the reaction and restrain the side reactions. The yield reduces sharply with the increase of filling water. Too much water would break the IL system and rebuild the hydrogen bond between the sugars.

\section{Conclusion}

We can get the conclusion as follows.

(1) In this experiment ILs with acid as catalyst, as a kind of solvent, can effectively accelerate the hydrolytic reaction of straw.

(2) The yield of reducing sugar is $35.5 \mathrm{wt} \%$ under the condition of ILs as solvent and microwave heating, while the yield is just $19.8 \mathrm{wt} \%$ under the condition of water as solvent and conventional heat treatment.

(3) The best operating conditions are as follows: atmospheric conditions in closed environment, IL $[\mathrm{BMIM}] \mathrm{Cl}$ as solvent, $\mathrm{H}_{2} \mathrm{SO}_{4}$ (concentration $0.5 \mathrm{wt} \%)$ as catalyst, the straw to IL mass ratio of 0.08 , the straw to filling water mass ratio of 0.25 , and reaction temperature $150^{\circ} \mathrm{C}$.

\section{Conflict of Interests}

The authors declare no conflict of interests.

\section{Acknowledgment}

This work was financially supported by the High-Tech Research and Development Program (863 program) of China (2009AA03Z802, 2009AA03Z803).

\section{References}

[1] A. J. Ragauskas, C. K. William, B. H. Davision et al., "The path forward for biofuels and biomaterials," Science, vol. 311, pp. 484489, 2006.

[2] J. Xiao, L. Shen, Y. Zhang, and J. Gu, "Integrated analysis of energy, economic, and environmental performance of biomethanol from rice straw in China," Industrial and Engineering Chemistry Research, vol. 48, no. 22, pp. 9999-10007, 2009.

[3] N. Mosier, C. Wyman, B. Dale et al., "Features of promising technologies for pretreatment of lignocellulosic biomass," Bioresource Technology, vol. 96, no. 6, pp. 673-686, 2005.

[4] Y. Z. Zheng, H. M. Lin, and G. T. Tsao, "Pretreatment for cellulose hydrolysis by carbon dioxide explosion," Biotechnology Progress, vol. 14, no. 6, pp. 890-896, 1998.

[5] P. Hu, N. Han, X. Zhang et al., "Fabrication of $\mathrm{ZnO}$ nanorodassembled multishelled hollow spheres and enhanced performance in gas sensor," Journal of Materials Chemistry, vol. 21, no. 37, pp. 14277-14284, 2011.

[6] R. P. Swatloski, S. K. Spear, J. D. Holbrey, and R. D. Rogers, "Dissolution of cellose with ionic liquids," Journal of the American Chemical Society, vol. 124, no. 18, pp. 4974-4975, 2002. 
[7] S. Zhu, Y. Wu, Q. Chen et al., "Dissolution of cellulose with ionic liquids and its application: a mini-review," Green Chemistry, vol. 8, no. 4, pp. 325-327, 2006.

[8] P. Hu, S. S. Pramana, S. Cao et al., "Ion-induced synthesis of uniform single-crystalline sulphide-based quaternary-alloy hexagonal nanorings for highly efficient photocatalytic hydrogen evolution," Advanced Materials, vol. 25, no. 18, pp. 25672572, 2013.

[9] N. Winterton, "Solubilization of polymers by ionic liquids," Journal of Materials Chemistry, vol. 16, no. 44, pp. 4281-4293, 2006.

[10] P. Alvira, E. Tomás-Pejó, M. Ballesteros, and M. J. Negro, "Pretreatment technologies for an efficient bioethanol production process based on enzymatic hydrolysis: a review," Bioresource Technology, vol. 101, no. 13, pp. 4851-4861, 2010.

[11] T. Heinze, K. Schwikal, and S. Barthel, "Ionic liquids as reaction medium in cellulose functionalization," Macromolecular Bioscience, vol. 5, no. 6, pp. 520-525, 2005.

[12] A. P. Dadi, S. Varanasi, and C. A. Schall, "Enhancement of cellulose saccharification kinetics using an ionic liquid pretreatment step," Biotechnology and Bioengineering, vol. 95, no. 5, pp. 904910, 2006.

[13] M. Toda, A. Takagaki, M. Okamura et al., "Green chemistry: biodiesel made with sugar catalyst," Nature, vol. 438, no. 7065, p. 178, 2005.

[14] A. Onda, T. Ochi, and K. Yanagisawa, "Selective hydrolysis of cellulose into glucose over solid acid catalysts," Green Chemistry, vol. 10, no. 10, pp. 1033-1037, 2008.

[15] Z. Zhang and Z. K. Zhao, "Solid acid and microwave-assisted hydrolysis of cellulose in ionic liquid," Carbohydrate Research, vol. 344, no. 15, pp. 2069-2072, 2009.

[16] P. Hu, X. Zhang, N. Han, W. Xiang, Y. Cao, and F. Yuan, "Solution-controlled self-assembly of $\mathrm{ZnO}$ nanorods into hollow microspheres," Crystal Growth \& Design, vol. 11, no. 5, pp. 15201526, 2011.

[17] X. Wang, H. Li, Y. Cao, and Q. Tang, "Cellulose extraction from wood chip in an ionic liquid 1-allyl-3-methylimidazolium chloride (AmimCl)," Bioresource Technology, vol. 102, no. 17, pp. 7959-7965, 2011.

[18] H. Wang, M. L. Maxim, G. Gurau, and R. D. Rogers, "Microwave-assisted dissolution and delignification of wood in 1-ethyl3-methylimidazolium acetate," Bioresource Technology, vol. 136, pp. 739-742, 2013.

[19] K. Ninomiya, T. Yamauchi, C. Ogino et al., "Microwave pretreatment of lignocellulosic material in cholinium IL for efficient enzymatic saccharification," Biochemical Engineering Journal, vol. 90, no. 15, pp. 90-95, 2014.

[20] P. Hu, N. Han, D. Zhang, J. C. Ho, and Y. Chen, "Highly formaldehyde-sensitive, transition-metal doped $\mathrm{ZnO}$ nanorods prepared by plasma-enhanced chemical vapor deposition," Sensors and Actuators B: Chemical, vol. 169, pp. 74-80, 2012.

[21] L. Li, S.-T. Yu, F.-S. Liu, C.-X. Xie, and C.-Z. Xu, "Cellulose in aqueous-ionic liquid media by microwave pretreatment," BioResources, vol. 6, no. 4, pp. 4494-4504, 2011.

[22] S. H. Ha, N. L. Mai, G. An, and Y.-M. Koo, "Microwaveassisted pretreatment of cellulose in ionic liquid for accelerated enzymatic hydrolysis," Bioresource Technology, vol. 102, no. 2, pp. 1214-1219, 2011.

[23] Y. Zhang, H. Du, X. Qian, and E. Y.-X. Chen, "Ionic liquidwater mixtures: enhanced $\mathrm{Kw}$ for efficient cellulosic biomass conversion," Energy \& Fuels, vol. 24, no. 4, pp. 2410-2417, 2010.
[24] A. De La Hoz, Á. Díaz-Ortiz, and A. Moreno, "Microwaves in organic synthesis. Thermal and non-thermal microwave effects," Chemical Society Reviews, vol. 34, no. 2, pp. 164-178, 2005. 

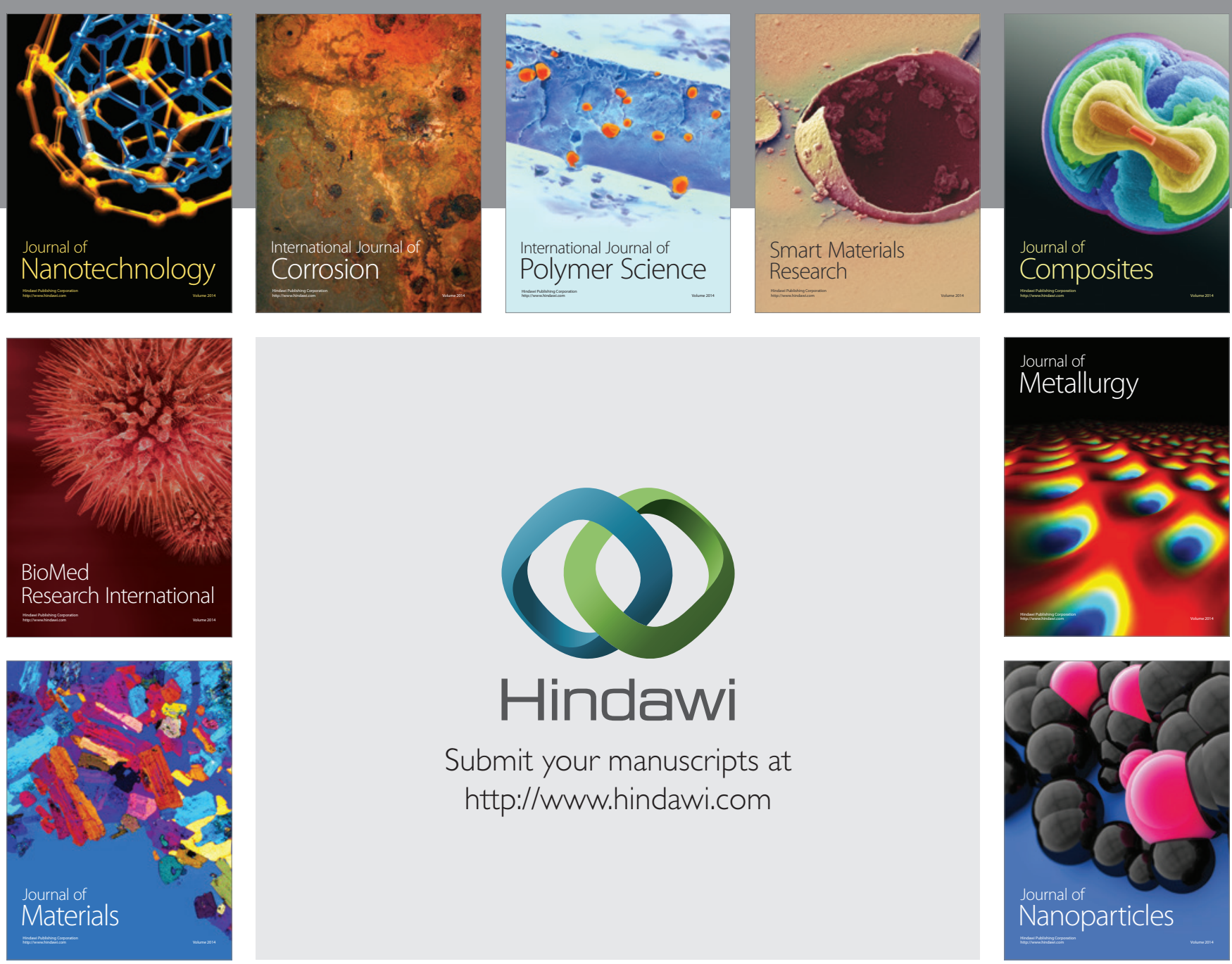

Submit your manuscripts at http://www.hindawi.com
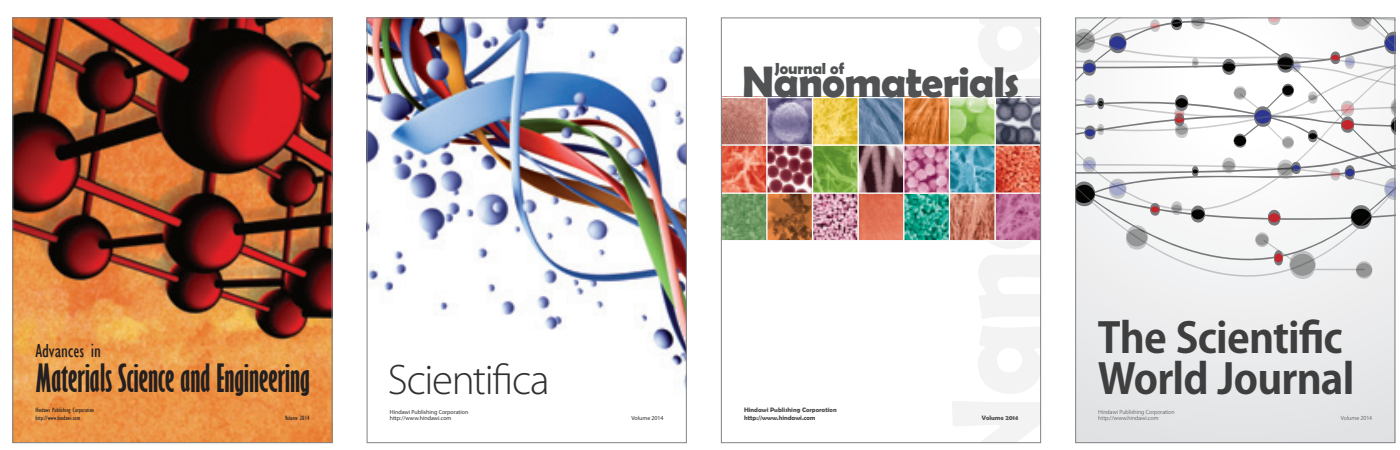

\section{The Scientific World Journal}
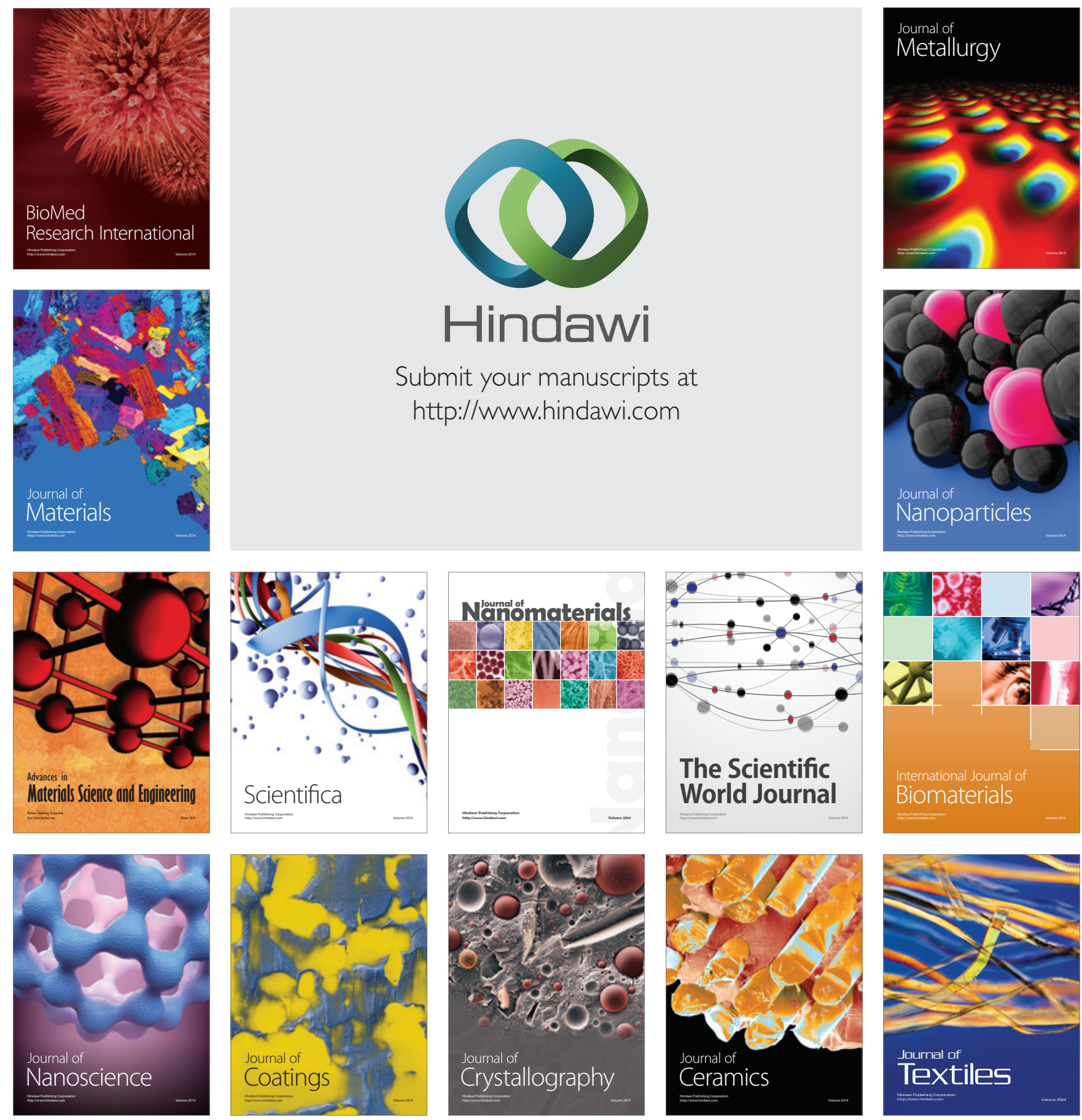